\title{
Improving hydrological and vegetation modelling using regional model calibration schemes together with remote sensing data
}

\author{
$\underline{\text { Y.Q. Zhang }}^{\text {a }}$, N.R. Viney, ${ }^{\text {, }}$, F.H.S Chiew ${ }^{\text {a }}$, A.I.J.M. van Dijk ${ }^{\text {a }}$, and Y.Y. Liu ${ }^{\text {b }}$ \\ ${ }^{a}$ CSIRO Water for a Healthy Country National Research Flagship, CSIRO Land and Water, P.O. Box 1666, \\ Clunies Ross Street, Canberra, ACT 2601 \\ ${ }^{b}$ School of Civil and Environmental Engineering, University of New South Wales, Sydney, Australia \\ Email: yongqiang.zhang@,csiro.au
}

\begin{abstract}
Remotely sensed data are widely used for estimating hydrological variables, such as land surface soil moisture, land surface evapotranspiration and catchment runoff because they provide temporally dynamic and spatially explicit information on land surface characteristics. Passive microwave observations have been used to infer surface soil moisture information because they are not affected by cloud cover and there is a physical relationship relating emissions to soil water. Remote sensing vegetation cover types and leaf area index time series data have been used as inputs into distributed, semi-distributed and lumped hydrological models (Liu et al., 2007).
\end{abstract}

This paper investigates the potential to improve runoff, soil moisture and vegetation dynamics predictions in ungauged catchments using a land surface hydrological model, AWRA-L, together with remotely sensed leaf area index measurements from NOAA-AVHRR and surface soil moisture measurements from TRMM-TMI. The study is conducted in 579 unregulated catchments across Australia. The AWRA-L model was regionally calibrated (i.e. a single set of parameters optimised) for half the catchments in four experiments: (1) against daily recorded streamflow data (Exp1); (2) against daily recorded streamflow together with monthly NOAAAVHRR leaf area index data (Exp2); (3) against daily recorded streamflow together with daily TRMM-TMI soil moisture data (Exp3); and (4) against all three data sets (Exp4). Next, the four optimised parameter sets obtained from the four regional calibration schemes were applied to the remaining half of the catchments for validation to evaluate the modelling skills for daily runoff and soil moisture predictions in independent catchments. This validation gives an indication of the abilities of the different calibration schemes to provide predictions in ungauged or poorly gauged catchments.

The results here show that (1) it is technically feasible (i.e. use of advanced scientific computing, such as CSIRO GPU cluster) to use regional model calibration for hydrological modelling for continental Australia; (2) the incorporation of remotely sensed data into the calibration objective function marginally improves the daily runoff estimates, but noticeably improves the leaf area index and soil moisture estimates in the validation catchments; (3) the biggest benefit comes from Exp4 calibrating against recorded runoff and remotely sensed leaf area index and soil moisture observations. This study is being extended to investigate regional calibration over hydroclimate regions (rather than across the whole of Australia) and in a gridded modelling application to better use the spatial remotely sensed data and to represent rainfall gradients within catchments. It is likely that this, together with adaptation of surface hydrological models to make better use of remotely sensed data, will improve runoff estimates across large regions and the impact of climate and land use changes on runoff.

It is noted that the global optimiser, the genetic algorithm toolbox built in MATLAB $®$ did not found global optimum for the regional model calibration scheme one. Nevertheless, this should not noticeably impact the comparison results between the four regional calibration schemes in the validation catchments. This is an ongoing study. It needs to re-configure the optimiser to for obtaining better regional model calibrations.

Keywords: runoff, soil moisture, leaf area index, hydrological model, remote sensing, PUB 
Zhang et al., Improving hydrological and vegetation modelling using regional model calibration...

\section{INTRODUCTION}

Remotely sensed (RS) data are widely used for estimating hydrological processes, such as land surface soil moisture, land surface evapotranspiration and catchment runoff because they provide temporally dynamic and spatially explicit information on land surface characteristics. Among them, passive microwave observations have been widely used to detect surface soil moisture (SM) because they are not affected by cloud cover and there is a physical relationship relating emissions to water amounts in the environment. The Microwave Instrument (TMI) on board NASA's Tropical Rainfall Measuring Mission (TRMM) has provided operational passive microwave measurements, which have been successfully used to monitor drought in eastern Australia between 1998 and 2005 (Liu et al., 2007). Liu et al. (2007) found that TRMM-TMI satellite-observed soil moisture and vegetation density show strong correlation with El Niño in eastern Australia. Liu et al. (2009) further analysed spatial-temporal variations of SM over mainland Australia by using passive microwave observations by four satellites. Remote sensing vegetation cover types and leaf area index time series data have been used as inputs into distributed, semi-distributed and lumped hydrological models (Zhang and Chiew et al., 2009; Zhang et al., 2009). Zhang et al. (2009) used remotely sensed evapotranspiration estimates together with recorded streamflow to constrain rainfall-runoff model calibration and then used optimised parameter sets for runoff predictions. They found that the use of remotely sensed evapotranspiration data in calibration leads to improved daily or monthly runoff predictions in ungauged catchments (PUB).

Several studies have used regional model calibration for improving runoff estimates for ungauged catchments (Parajka et al., 2007). Regional model calibration is defined here as model calibration simultaneously against observations in multiple catchments (from dozens to hundreds) across a wide region to obtain a single parameter set for all catchments. In contrast, local model calibration is referred as the calibration against observations in a single catchment. The main benefit of regional model calibration is that one set of optimised parameter values is obtained (or perhaps several sets if different objective functions are considered or if a research region is divided into different sub regions) which can be used for improving hydrological and vegetation estimates at the regional scale. The major advantage of local model calibration is that an optimum parameter set can be obtained for each individual catchment, and will match the local data most accurately. However, the locally optimised parameter values are not always suitable for PUB because gauging stations can be few and far apart, in which case the underlying assumption that nearby catchments have similar responses can be problematic. Furthermore, observational errors (e.g. in streamflow gauging and rainfall inputs) can cause the local calibration to be biased, with biased model parameters being regionalized.

This paper investigates whether the inclusion of TRMM-TMI SM ( $\left.S M_{\mathrm{RS}}\right)$ and NOAA-AVHRR leaf area index $\left(L_{\mathrm{RS}}\right)$ data into four regional model calibration schemes for a land surface hydrology model, AWRA-L, can improve hydrological and vegetation estimates for continental Australia. Section 2.3 introduces the four regional calibration schemes in detail. Each scheme uses half of a large catchment dataset for the AWRA-L model calibration and uses the remaining half for model cross-validation. Data from 579 relatively unregulated catchments across continental Australia are used for this study (Figure 1).

\section{METHODS AND DATA}

\subsection{AWRA-L model}

The AWRA Landscape model (AWRA-L version 0.5; Van Dijk, 2010) is a grid-distributed biophysical model, developed to simulate water stores and flows in the vegetation, soil and local catchment groundwater systems. Model inputs include daily minimum temperature, maximum temperature, solar radiation, precipitation; model outputs include runoff, soil moisture at three soil layers (top, shallow and deep soils), surface evaporation and vegetation transpiration.

\subsection{Data}

Input climate data: Daily time series of maximum temperature, minimum temperature, incoming solar radiation and precipitation from 1980 to 2008 at $0.05^{\circ} \times 0.05^{\circ}(\sim 5 \mathrm{~km} \times 5 \mathrm{~km})$ grid cells from the SILO Data Drill of the Queensland Department of Natural Resources and Water (www.nrw.gov.au/silo) are used. The SILO Data Drill provides surfaces of daily rainfall and other climate data interpolated from point measurements made by the Australian Bureau of Meteorology.

Streamflow: Daily streamflow data for the 579 unregulated and not nested catchments (50 to $\left.5000 \mathrm{~km}^{2}\right) \mathrm{come}$ from state water agencies. The streamflow data used here are quality controlled (Zhang et al., 2011). Streamlfow data from 1981 to 2008 are used in this study. 
Zhang et al., Improving hydrological and vegetation modelling using regional model calibration...

Soil moisture: Daily time series of TRMM-TMI top soil moisture content data from 2000 to 2008 at $0.25^{\circ} \times$ $0.25^{\circ}(\sim 25 \mathrm{~km} \times 25 \mathrm{~km})$ are used (Liu et al., 2009). The data were retrieved using the land parameter retrial model and X-band brightness temperature. The retrieved soil moisture represents an estimate of the moisture content of roughly the top 2-5 centimetres of soil.

LAI: Monthly time series of NOAA-AVHRR leaf area index data at $\sim 8-\mathrm{km}$ resolution from 1981 to 2006 (Ganguly et al., 2008) obtained from Boston University are used in Exp2 and Exp4 to constrain model calibration.

For each of the 579 catchments, all gridded data were arithmetically averaged to obtain catchment aggregated values at each daily time step (monthly in the case of LAI). The aggregated daily meteorological data together with daily observed runoff, aggregated monthly $L_{\mathrm{RS}}$ and aggregated daily $S M_{\mathrm{RS}}$ data are input into the AWRA-L model for model calibration and validation.

\subsection{Model calibration and validation}

A global optimisation method, the genetic algorithm, is used to optimise 28 parameters (20 hydrological response unit parameters and 8 univeral parameters) in the AWRA-L model. Out of the 579 catchments, 290 catchments are randomly selected for model calibration and the rest 289 catchments are used for model crossvalidation (Figure 1).

Four experiments for model calibration are conducted. The experiment 1 calibrates AWRAL-L against runoff only (taken as a benchmark), while the other three calibrate the model against runoff and remote sensing leaf area index and soil moisture observations. The simulation period is from 1 January 1980 to 31 December 2008 , with the first year (1980) used for model warmup and the rest (1981-2008) for model calibration and evaluation. The experiments 1-4 are thereafter labelled as Exp1, Exp2, Exp3 and Exp4. They are given by

- Exp1: the benchmark experiment, model calibration against daily recorded runoff $(Q)$ (1981-2008);

- $\quad$ Exp2: model calibration against daily recorded $Q$ (1981-2008) and monthly NOAA-AVHRR $L_{\mathrm{RS}}$ data (1981-2006);

- $\quad$ Exp3: Model calibration against daily recorded $Q$ (1981-2008) and daily TRMM-TMI $S M_{\mathrm{RS}}$ data (2000-2008);

- $\quad$ Exp4: Model calibration against daily recorded $Q$ (1981-2008), monthly NOAA-AVHRR $L_{\mathrm{RS}}$ (1981-2006) and daily TRMM-TMI $S M_{\mathrm{RS}}$ data (2000-2008).

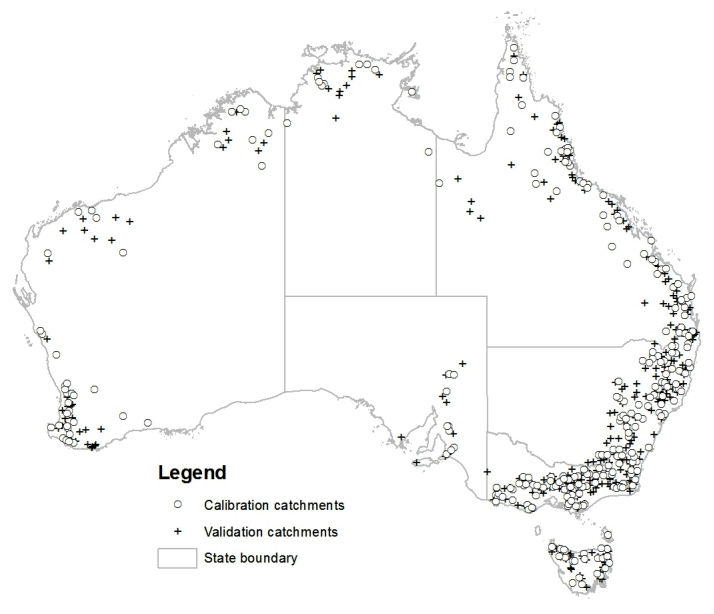

Figure 1. Spatial coverage of 579 unregulated catchments across Australia, including 290 calibration catchments and 289 validation catchments.

The four optimised parameter sets obtained from the four regional calibration experiments are then applied to the remaining 289 catchments (Figure 1) and predictions are evaluated for the same period as calibrations. These validation results can be used to evaluate the skill of each parameter set in predicting hydrological and vegetation dynamics in ungauged catchments.

Two steps are carried out for each regional calibration scheme. First, in each calibration catchment the AWRA-L model is calibrated against observations by minimising an objective function $(F)($ Eqs. (2) - (6)). Then, a composite summary or 'grand' objective function $\left(F_{g}\right)$ is calculated by considering percentiles from the 290 objective function values:

$$
F_{g}=F_{1 \%}+F_{25 \%}+F_{50 \%}+F_{75 \%}
$$

where $F_{1 \%}, F_{25 \%}, F_{50 \%}$ and $F_{75 \%}$ are the $1^{\text {st }}, 25^{\text {th }}$, median and $75^{\text {th }}$ percentiles of the objective function values, respectively. With a higher percentile (i.e., a higher $F$ value), a catchment has poorer simulated runoff results. The calibration process then optimises the model parameters to minimise $F_{g}$. The $90^{\text {th }}$ is not used in Eq. (1) because $F$ values for over $90^{\text {th }}$ catchments are 1-2 orders of magnitude higher than those for lower percentile catchments. Thus, using $90^{\text {th }}$ puts poorly calibrated catchments much more weight than well calibrated 
Zhang et al., Improving hydrological and vegetation modelling using regional model calibration...

catchments. The regional calibration requires high amount of calculation resource. As such, 280 processers (2.8GHz compute cores) the CSIRO GPU cluster are used for parallel computation in regional model calibration.

The objective function calculated for each calibration catchment is introduced below.

\subsubsection{Exp1 - benchmark calibration against runoff}

In Exp1, the objective function $\left(F_{l}\right)$ for a single catchment depends on the 1- NSE (Nash-Sutcliffe Efficiency) and a logarithmic function of bias (Viney et al., 2009) and is given by

$$
F_{1}=(1-N S E)+5|\ln (1+B)|^{2.5}
$$

where $B$ is the bias, defined as the total model error divided by total observed runoff. NSE measures the agreement between the modelled and observed daily values, with $N S E=1.0$ indicating perfect agreement between the modelled and observed daily runoff at a given catchment.

\subsubsection{Exp2 - calibration against runoff and leaf area index}

In Exp2, the AWRA-L model is calibrated against recorded daily runoff and monthly $L_{\mathrm{RS}}$. The objective function $\left(F_{2}\right)$ for a single catchment is given as

$$
F_{2}=(1-N S E)+5|\ln (1+B)|^{2.5}+\left(1-R_{L}^{2}\right)
$$

where $R_{\mathrm{L}}^{2}$ is the coefficient of determination in the monthly simulated and remotely sensed $L_{\mathrm{RS}} \cdot R_{\mathrm{L}}^{2}$ was used for leaf area index instead of the NSE because although the simulated and remotely sensed leaf area index may not have the exact same definition and hence the same values, they should be strongly correlated (Zhang et al., 2009).

2.3.3. Exp3 - calibration against runoff and soil moisture

In Exp3, the AWRA-L model is calibrated against recorded daily runoff and daily $S M_{\mathrm{RS}}$. The objective function $\left(F_{3}\right)$ for a single catchment is given as

$$
F_{3}=(1-N S E)+5|\ln (1+B)|^{2.5}+\left(1-R_{S M}^{2}\right)
$$

where $R_{\mathrm{SM}}^{2}$ is the coefficient of determination in the simulated daily top-layer soil moisture and $S M_{\mathrm{RS}}$.

2.3.4. Exp4 - calibration against runoff, leaf area index and soil moisture

In Exp4, the AWRA-L model is calibrated against recorded daily runoff, monthly $L_{\mathrm{RS}}$ and daily $S M_{\mathrm{RS}}$. The objective function $\left(F_{4}\right)$ for a single catchment is given as

$$
F_{4}=(1-N S E)+5|\ln (1+B)|^{2.5}+\left(1-R_{L}^{2}\right)+\left(1-R_{S M}^{2}\right)
$$

\section{RESULTS AND DISCUSSION}

Table 1 summarises model calibration and validation results for the four modelling experiments, $10^{\text {th }}, 25^{\text {th }}$, median, $75^{\text {th }}$, and $90^{\text {th }}$ percentile daily runoff NSE, absolute water balance error (WBE), monthly leaf area index coefficient of determination $R_{\mathrm{L}}^{2}$ and daily soil moisture coefficient of determination $\left(R_{\mathrm{SM}}^{2}\right)$.

\subsection{Calibration results for runoff}

Regarding the NSE calibration results, at the $10^{\text {th }}$ percentile and below, the benchmark experiment Exp1 is the best (with highest NSE values). Above the $25^{\text {th }}$ percentile, Exp4 is slightly better than other three experiments. The model calibrations obtain similar WBE for the four experiments. The $F_{\mathrm{g}}$ value for runoff (Eqs. (1) and (2)) for Exp1 is almost as same (0.61) as that for Exp4, but slightly lower than 0.64 for Exp2 and Exp3. These results suggest that Exp1 and Exp4 show the overall similar performance in runoff calibrations. The differences between the four experiments, however, are marginal.

These calibration results at the 290 catchments are noticeably poorer than those obtained from traditional rainfall-runoff models, such as GR4J model which is locally calibrated using $F_{1}$ (Eq. (2)). The median NSE of daily runoff for the four experiments for AWRA-L is about 0.17-0.21 poorer than that for GR4J and the median WBE for AWRA-L is 0.40 poorer (higher) than those for GR4J. It is noted that the traditional rainfall-runoff models are calibrated for individual catchments, i.e., one set of optimised parameter values for 
Zhang et al., Improving hydrological and vegetation modelling using regional model calibration...

each catchment. In this study the AWRA-L model is regionally calibrated, i.e., one set of optimised parameter values for all the 290 calibration catchments.

Table 1. Statistical summary of model calibration and prediction results for four modelling experiments for AWRA-L and GR4J

\begin{tabular}{|c|c|c|c|c|c|c|c|c|c|c|c|c|}
\hline \multirow{2}{*}{$\begin{array}{c}\text { Evaluation } \\
\text { criteria }\end{array}$} & \multirow{2}{*}{$\begin{array}{c}\text { modelling } \\
\text { experiments }\end{array}$} & \multirow{2}{*}{$\begin{array}{c}\text { Calibration } \\
\text { variables }\end{array}$} & \multicolumn{5}{|c|}{ Calibration (percentile) } & \multicolumn{5}{|c|}{ Prediction (percentile) } \\
\hline & & & 10 & 25 & 50 & 75 & 90 & 10 & 25 & 50 & 75 & 90 \\
\hline \multirow{5}{*}{ NSE } & Exp1 & $\mathrm{Q}$ & 0.06 & 0.27 & 0.44 & 0.56 & 0.65 & 0.14 & 0.27 & 0.40 & 0.54 & 0.64 \\
\hline & Exp2 & $\mathrm{Q}+L_{\mathrm{RS}}$ & -0.08 & 0.28 & 0.45 & 0.56 & 0.64 & 0.13 & 0.29 & 0.42 & 0.55 & 0.64 \\
\hline & Exp3 & $\mathrm{Q}+S M_{\mathrm{RS}}$ & 0.01 & 0.27 & 0.42 & 0.56 & 0.63 & 0.11 & 0.26 & 0.40 & 0.53 & 0.64 \\
\hline & Exp4 & $\mathrm{Q}+S M_{\mathrm{RS}}+L_{\mathrm{RS}}$ & -0.04 & 0.27 & 0.46 & 0.57 & 0.66 & 0.12 & 0.27 & 0.44 & 0.56 & 0.66 \\
\hline & GR4J & $\mathrm{Q}$ & 0.34 & 0.51 & 0.63 & 0.72 & 0.79 & 0.04 & 0.27 & 0.46 & 0.61 & 0.72 \\
\hline \multirow{5}{*}{$W B E$} & Exp1 & $\mathrm{Q}$ & 5.2 & 12.8 & 24.7 & 43.1 & 76.6 & 5.1 & 12.1 & 27.0 & 47.7 & 80.0 \\
\hline & Exp2 & $\mathrm{Q}+L_{\mathrm{RS}}$ & 5.4 & 14.5 & 25.8 & 45.3 & 89.1 & 5.8 & 12.5 & 24.4 & 50.7 & 88.6 \\
\hline & Exp3 & $\mathrm{Q}+S M_{\mathrm{RS}}$ & 4.9 & 13.2 & 25.7 & 43.1 & 87.5 & 6.2 & 12.4 & 27.1 & 49.4 & 92.3 \\
\hline & Exp4 & $\mathrm{Q}+S M_{\mathrm{RS}}+L_{\mathrm{RS}}$ & 6.2 & 13.1 & 24.3 & 43.8 & 74.1 & 5.5 & 12.9 & 26.9 & 50.2 & 86.2 \\
\hline & GR4J & $\mathrm{Q}$ & 0.77 & 1.6 & 3.0 & 4.8 & 6.3 & 3.9 & 10.9 & 23.5 & 45.0 & 76.2 \\
\hline \multirow{4}{*}{$\mathrm{R}_{\mathrm{L}}^{2}$} & Exp1 & $\mathrm{Q}$ & 0.00 & 0.02 & 0.07 & 0.22 & 0.39 & 0.00 & 0.01 & 0.06 & 0.19 & 0.33 \\
\hline & Exp2 & $\mathrm{Q}+L_{\mathrm{RS}}$ & 0.00 & 0.02 & 0.17 & 0.41 & 0.60 & 0.00 & 0.02 & 0.14 & 0.40 & 0.57 \\
\hline & Exp3 & $\mathrm{Q}+S M_{\mathrm{RS}}$ & 0.00 & 0.02 & 0.06 & 0.17 & 0.29 & 0.00 & 0.01 & 0.05 & 0.14 & 0.24 \\
\hline & Exp4 & $\mathrm{Q}+S M_{\mathrm{RS}}+L_{\mathrm{RS}}$ & 0.00 & 0.02 & 0.11 & 0.37 & 0.55 & 0.00 & 0.01 & 0.08 & 0.29 & 0.49 \\
\hline \multirow{4}{*}{$\mathrm{R}_{\mathrm{SM}}^{2}$} & Exp1 & Q & 0.03 & 0.13 & 0.36 & 0.55 & 0.67 & 0.05 & 0.17 & 0.37 & 0.56 & 0.65 \\
\hline & Exp2 & $\mathrm{Q}+L_{\mathrm{RS}}$ & 0.03 & 0.14 & 0.33 & 0.49 & 0.59 & 0.05 & 0.15 & 0.32 & 0.49 & 0.58 \\
\hline & Exp3 & $\mathrm{Q}+S M_{\mathrm{RS}}$ & 0.03 & 0.13 & 0.36 & 0.56 & 0.67 & 0.05 & 0.17 & 0.36 & 0.56 & 0.65 \\
\hline & Exp4 & $\mathrm{Q}+S M_{\mathrm{RS}}+L_{\mathrm{RS}}$ & 0.04 & 0.16 & 0.41 & 0.59 & 0.70 & 0.06 & 0.20 & 0.38 & 0.61 & 0.68 \\
\hline
\end{tabular}

\subsection{Calibration results for leaf area index and soil moisture}

For LAI, it is clear that Exp2 calibrating against $Q$ and $L_{\mathrm{RS}}$ performs best in modelling leaf area index time series (according to $\mathrm{R}_{\mathrm{L}}^{2}$ ) and Exp4 calibrating against $Q, L_{\mathrm{RS}}$ and $S M_{\mathrm{RS}}$ is the second best. For soil moisture, Exp4 calibrating against runoff, $L_{\mathrm{RS}}$ and $S M_{\mathrm{RS}}$ is the best, in terms of highest $\mathrm{R}_{\mathrm{SM}}^{2}$ values. Exp3 calibrating against runoff and $S M_{\mathrm{RS}}$ is similar to Exp1 calibrating against runoff only, while Exp2 is the worst.

These calibration results for leaf area index and soil moisture suggest that that soil moisture has less weight than leaf area index in the objective functions (Eqs. (3)-(5)). This is because $\mathrm{R}_{S M}^{2}$ is noticeably higher than $\mathrm{R}_{\mathrm{L}}^{2}$ at the same percentile. For instance, the median $\mathrm{R}_{\mathrm{SM}}{ }_{\mathrm{S}}$ is about 0.2-0.3 higher than the median $\mathrm{R}_{\mathrm{L}}^{2}$. This automatically puts more weight on leaf area index when minimising the objective functions. However, this means that there is greater potential for improvements in $\mathrm{R}_{\mathrm{L}}^{2}$ because of its greater spread of values at each percentile.

\subsection{Predictions of daily runoff}

Figures 2 and 3 and Table 1 summarise model validation (or prediction) results of daily runoff for the four modelling experiments. Significantly, for all experiments, model validation results are very similar to model calibration results, i.e. no significant degradation from calibration to prediction (as is typically the case with nearest neighbour regionalization). Another striking aspect is that at the $10^{\text {th }}$ percentile NSE of daily runoff for validation is about 0.08-0.21 higher than that for calibration (Table 1). The comparison of prediction results for the four experiments indicates that the NSE and WBE accumulation curves are marginally different between the alternative modelling experiments.

The prediction results shown here are comparable to, but poorer than, those obtained by GR4J model. Figures 2 and 3 compare between AWRA-L results to those obtained by using a widely used regionalisation approach, nearest neighbor approach, and GR4J model for the 289 prediction catchments. For the percentiles over the $25^{\text {th }}$, NSE of daily runoff for GR4J are about $0.02-0.1$ higher than those for AWRA-L while for the percentiles below $25^{\text {th }}$, the NSE of daily runoff for AWRA-L is about $0.05-0.1$ higher than those for GR4J. The WBE accumulative curve comparisons show that GR4J got marginally better WBE results (about 0.03 higher) than the four experiments for AWRA-L. It is noted that there is a noticeable degradation from calibration and prediction for GR4J, but not for AWRA-L. 


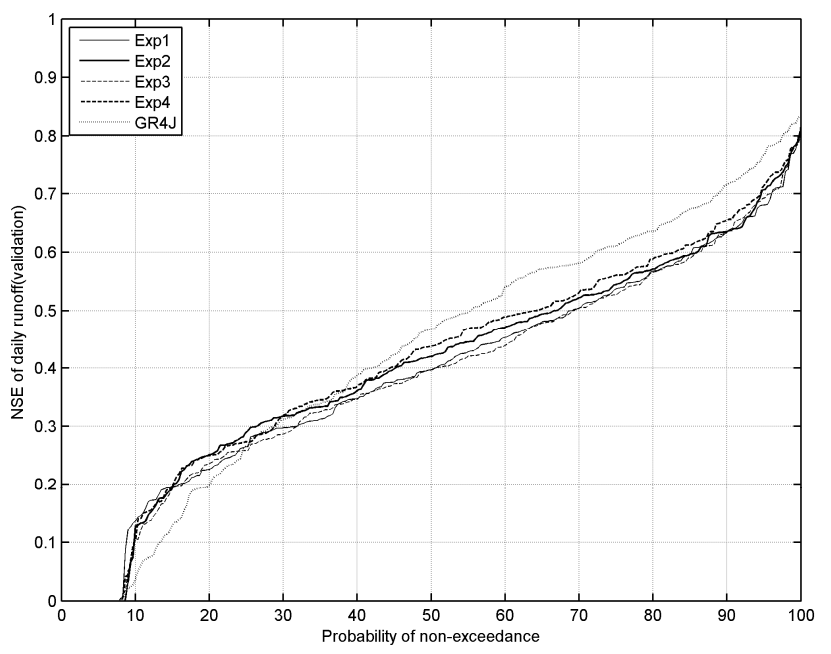

Figure 2. Summary of predicted NSE of daily runoff for the four modelling experiments. Large NSE values indicate a good model performance.

\subsection{Predictions of monthly leaf area index}

Figure 4 and Table 1 summarise model prediction results of monthly leaf area index for the four modelling experiments. For each experiment, model prediction results are slightly degraded from model calibration results. The comparison between the four experiments for model validation shows very similar results to that for model calibration. Exp2 calibrating against $Q$ and $L_{\mathrm{RS}}$ is the best in predicting monthly leaf area and Exp 4 calibrating against $Q, L_{\mathrm{RS}}$ and $S M_{\mathrm{RS}}$ is slightly worse than Exp2, but much outperforms Exp1 and Exp3.

\subsection{Predictions of daily soil moisture}

Figure 5 and Table 1 summarise model prediction results of daily surface soil moisture for the four modelling experiments. The results of $\mathrm{R}_{\mathrm{SM}}^{2}$ are not appreciably degraded from calibration to validation for each experiment. Exp4 calibrating against all three variables $\left(Q, L_{\mathrm{RS}}\right.$ and $\left.S M_{\mathrm{RS}}\right)$ shows the best estimates of surface daily soil moisture; Exp3 calibrating against $Q$ and $S M_{\mathrm{RS}}$ is similar to Exp1 calibrating against $Q$ only; Exp2 calibrating against $Q$ and $L_{\mathrm{RS}}$ performs worst. It is noted that the difference between the experiments for predicting daily soil moisture is smaller than that for predicting monthly leaf area index. It, however, is larger than the difference between the experiments for predicting runoff.

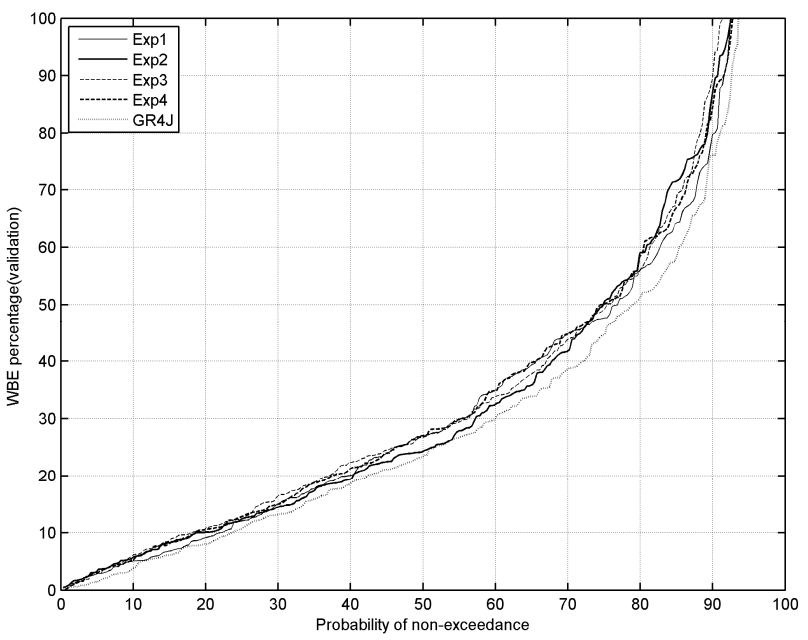

Figure 3. Summary of predicted WBE percentage for the four modelling experiments. Small WBE values indicate a good model performance.

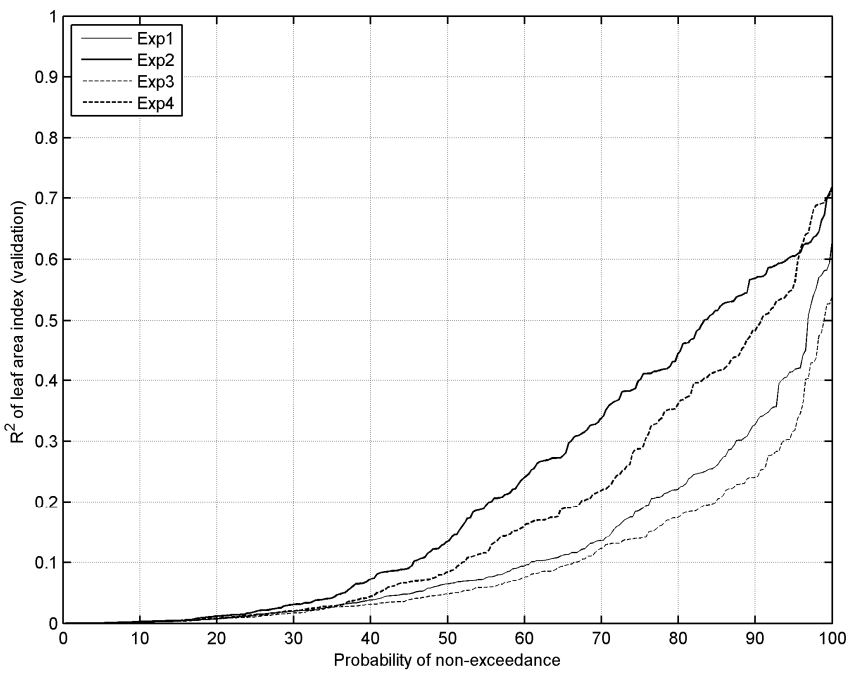

Figure 4. Summary of predicted $\mathrm{R}^{2}$ of leaf area index for the four modelling experiments. Large $\mathrm{R}_{\mathrm{L}}^{2}$ values indicate a good model performance.

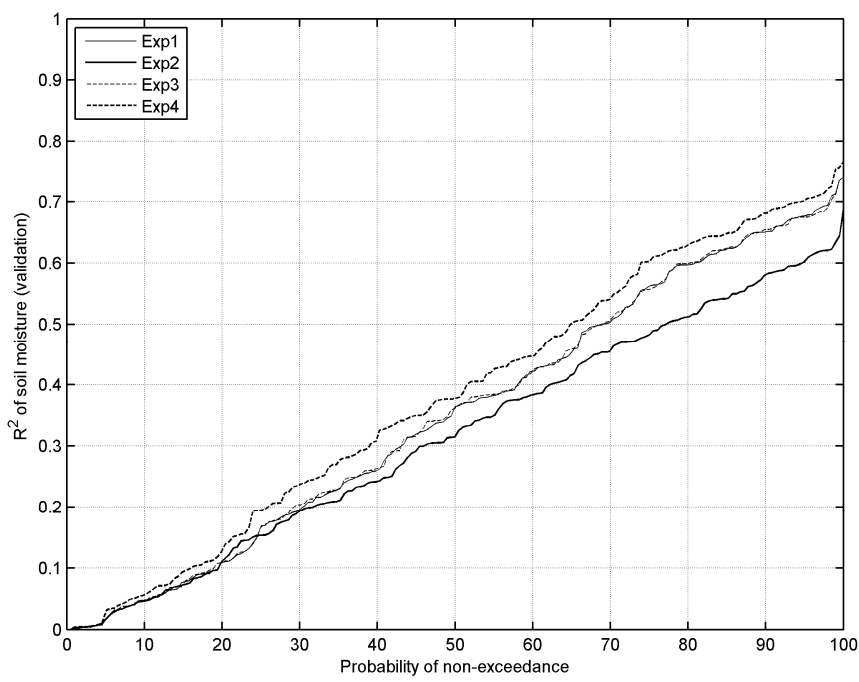

Figure 5. Summary of predicted $\mathrm{R}^{2}$ of daily soil moisture for the four modelling experiments. Large $\mathrm{R}^{2}{ }_{S M}$ values indicate a good model performance. 
The predictions of daily runoff, monthly leaf area index and daily soil moisture suggest that incorporation of remote sensing leaf area index and soil moisture into hydrological model calibration can improve model general performance in simulating hydrological and vegetation process, compared to the benchmark calibration against recorded daily runoff only. The biggest benefit found in this study is from Exp4 calibrating against $Q, L_{\mathrm{RS}}$ and $S M_{\mathrm{RS}}$ observations.

\section{CONCLUSIONS}

This study investigates the potential to incorporate remote sensing leaf area index and soil moisture data into four regional model calibration schemes for improving hydrological and vegetation dynamic estimates for continental Australia. The calibration and predictions result show that (1) it is technically feasible (i.e. use of advanced scientific computing, such as CSIRO GPU cluster) to use regional model calibration into hydrological modelling at a continental scale; (2) the incorporation of remotely sensed data into the calibration objective function only very marginally improves the daily runoff estimates, but noticeably improves the leaf area index and soil moisture estimates in ungauged catchments; (3) the biggest benefit comes from model calibration against recorded runoff, remotely sensed leaf area index and soil moisture observations.

This is a first attempt, in our knowledge, to use remotely sensed leaf area index and microwave soil moisture data together with runoff data for regional model calibration and prediction. More work needs to be done on how to effectively incorporate gridded remote sensing leaf area index and soil moisture measurements into hydrological models. Furthermore, the global optimiser, the genetic algorithm toolbox built in MATLAB ${ }^{\circledR}$ did not found the global optimum for the regional model calibration scheme one. It needs to re-configure the optimiser to for obtaining better regional model calibrations.

\section{ACKNOWLEDGMENTS}

This study is carried out in the CSIRO Water for Healthy Country National Research Flagship and is supported by the Water Information Research and Development Alliance between CSIRO and the Australian Bureau of Meteorology.

\section{REFERENCES}

Ganguly, S., Samanta, A., Schull, M. A., Shabanov, N. V., Milesi, C., Nemani, R. R., Knyazikhin, Y. \& Myneni, R.B. 2008: Generating vegetation leaf area index Earth system data record from multiple sensors. Part 2: Implementation, analysis and validation. Remote Sensing of Environment, 112, 43184332.

Liu, Y., de Jeu, R.A.M., van Dijk, A. \& Owe, M. (2007) TRMM-TMI satellite observed soil moisture and vegetation density (1998-2005) show strong connection with El Nino in eastern Australia. Geophysical Research Letters, L15401, 10.1029/2007gl030311.

Liu, Y.Y., van Dijk, A., de Jeu, R.A.M. \& Holmes, T.R.H. (2009) An analysis of spatiotemporal variations of soil and vegetation moisture from a 29-year satellite-derived data set over mainland Australia. Water Resources Research, W07405, 10.1029/2008wr007187.

Parajka, J., Bloschl, G., and Merz, R. (2007). Regional calibration of catchment models: Potential for ungauged catchments. Water Resources Research, W06406, Artn w06406.

van Dijk, A. (2010) The Australian water resources assessment system, Technical Report 3. Landscape Model (version 0.5) Technical Description. CSIRO Water for a Healthy Country, Canberra. Available at http:/www.clw.csiro.au/publications/waterforahealthycountry/2010/wfhc-aus-water-resourcesassessment-system.pdf.

Viney, N. R., Perraud, J., Vaze, J., Chiew, F. H. S., Post, D. A., and Yang, A., 2009: The usefulness of bias constraints in model calibration for regionalisation to ungauged catchments. 18th World IMACS Congress and MODSIM09 International Congress on Modelling and Simulation: Interfacing Modelling and Simulation with Mathematical and Computational Sciences, 3421-3427.

Zhang, Y. Q. and Chiew, F. H. S. (2009). Relative merits of different methods for runoff predictions in ungauged catchments. Water Resources Research, 45, W07412, doi:10.1029/2008WR007504.

Zhang, Y. Q., Chiew, F. H. S., Zhang, L., and Li, H. X. (2009). Use of remotely sensed actual evapotranspiration to improve rainfall-runoff modelling in southeast Australia. Journal of Hydrometeorology, DOI: 10.1175/2009JHM1061.1.

Zhang, Y.Q., Viney, N., Chen, Y., Li, H. Y. 2011. Collation of streamflow data for 719 unregulated Australian catchments. CSIRO: Water for a Healthy Country National Research Flagship, 67pp. (in review) 